Research Article

\title{
Experimental Study of the Mechanical Characteristics of a Rock-Like Material Containing a Preexisting Fissure under Loading and Unloading Triaxial Compression
}

\author{
Taoli Xiao ${ }^{(D)},{ }^{1}$ Mei Huang ${ }^{(D},{ }^{1}$ and Min Gao $\mathbb{D}^{2}$ \\ ${ }^{1}$ School of Urban Construction, Yangtze University, Jingzhou, Hubei, China \\ ${ }^{2}$ State Key Laboratory of Coastal and Offshore Engineering, Dalian University of Technology, Dalian, Liaoning, China
}

Correspondence should be addressed to Mei Huang; 201772357@yangtzeu.edu.cn

Received 8 September 2019; Revised 11 November 2019; Accepted 27 November 2019; Published 29 February 2020

Academic Editor: Farhad Aslani

Copyright (c) 2020 Taoli Xiao et al. This is an open access article distributed under the Creative Commons Attribution License, which permits unrestricted use, distribution, and reproduction in any medium, provided the original work is properly cited.

\begin{abstract}
An experimental study of a rock-like material containing a preexisting fissure subjected to loading and unloading triaxial compression is carried out, and the results show that the mechanical characteristics of the rock-like specimen depend heavily on the loading paths and the inclination of the fissure. The triaxial loading experiment results show that the failure strength linearly increases, while the residual strength linearly decreases with increasing inclination. Furthermore, specimens subjected to triaxial compression show an " $X$ "-type shear failure mode. The triaxial unloading compression experimental results show that specimens with different inclination angles have various failure modes. Specimens with gentle inclinations show a tensile-shear mix failure mode, specimens with middle inclinations show a shear-sliding failure mode, and specimens with steep inclinations show a tensile failure mode. These findings can be used to forecast excavation-induced instabilities in deep underground engineering rock structures.
\end{abstract}

\section{Introduction}

Excavation-induced instability and failure of deep underground rock structures are closely associated with the mechanical behavior of rock masses exposed to loading and unloading of the confining pressure [1]. It is well known that natural rock masses contain fissures, pores, and weak planes that usually lead to the failure of rock masses under loading or unloading conditions. Rock discontinuities are fundamentally important to most rock engineering projects [2]. Shang et al. addressed the issue of tensile strength of incipient discontinuities in rock and presented results from a laboratory test programme to quantify this parameter [3, 4]. Xiao et al. studied the mechanical and deformation behaviors of the fractured rock-like material with one single fissure under the conventional triaxial compression [5]. Peng et al. [6] comprehensively investigated the geometrical influence of two nonparallel fissures on the mechanical behaviors of rock-like specimens. Wong and Einstein studied the cracking and coalescence processes between preexisting artificial flaws [7]. Clearly, it is of great importance to illustrate the effect of loading and unloading triaxial compressions on the mechanical behavior of rock masses and to disclose the fundamentals of excavation-induced instability.

Previous studies emphasized the mechanical behavior of intact rocks under loading and unloading conditions. By conducting uniaxial and triaxial cyclic loading and unloading tests, Elliott and Brown [8] studied the elastic and plastic behaviors of rocks. Hua and You [9] studied the energy release of rocks during unloading failure and noted that the rapid release of a large amount of elastic energy resulted in failure before unloading. Tao et al. [10] analyzed the unloading process of rocks under a high initial stress using a mathematical model. Meng et al. [11] studied the energy evolution over the entire process of rock deformation and failure under uniaxial cyclic loading and unloading compression at six loading rates. Ding et al. [12] investigated the mechanical behavior of sandstone under unloading conditions and found that the bearing ability decreased gradually due to the unloading of the confining pressure. Chen et al. [13] reported that the volume deformation of halite under unloading conditions was greater than that 
under triaxial loading conditions. Liu et al. [14] investigated the effect of confining pressure unloading on the strength reduction of soft coal for a borehole stability analysis. The abovementioned studies uncovered the strong influence of the unloading process on the strength and failure modes of rocks. Therefore, it is of great practical significance to take loading and unloading conditions into consideration and to study the deformation and mechanical behaviors of fractured rock masses.

Researchers have conducted experiments on the crack coalescence of real rock specimens or rock-like material specimens containing fissures [15-20]. It was found that the fissure geometry strongly influences the cracking and coalescence.

Liu et al. [21] considered the influence of different random compression cycles and studied the mechanical fatigue response of synthetic intermittently fissured rocks. Five crack coalescence patterns were observed in their study based on the interaction between two adjacent fissures. Feng [22] studied the mechanical behaviors of fissured specimens under coupled static and dynamic loads with different loading parameters, and their results showed that the higher dynamic strain rate and the higher static prestress on a specimen induced greater fractal dimensions of the crack in view of the cracking morphology. Wong and Chau [23] generalized three main crack coalescence modes, including a shear mode, a mixed shear/tensile mode, and a wing tensile mode. Wong and Einstein [24] categorized nine crack coalescence modes by considering more factors including the fissure inclination, bridge ligament angle, and fissure spacing. Theoretical and numerical models have also been developed to predict the growth, interaction, and failure of cracks in fractured rock masses [25-30]. However, it is of great importance to study the mechanical characteristics and failure modes of fractured specimens with preexisting fissures under loading and unloading triaxial compression.

This paper experimentally studies the mechanical behavior of the rock-like specimens containing preexisting fissures under loading and unloading triaxial compression. The deformation and failure modes of the specimens under different loading paths and the influence of the fissure inclination are investigated.

\section{Experimental Study}

2.1. Specimen Preparation. Considering the difficulty of directly prefabricating fissures in real rocks without inadvertently fracturing the specimen $[22,31]$, a rock-like material with a preexisting fissure is adopted as the study object. In this paper, the synthetic rock-like material consists of highstrength cement, sand, silicon powder, iron powder, waterreducing agent, and water, and their mass ratios are $1: 0.8$ : $0.13: 0.25: 0.02: 0.325$, respectively. Figure 1 shows the rocklike specimen with a preexisting fissure. Figure 2 shows the detailed process of preparing the rock-like specimens including those that are intact and those that are fractured. Jointed rock specimens with same dimensions were cast by pouring the mixed material into the mold. Then, the inserted steel sheets were removed from the mold after 6 hours. The specimen blocks were placed in a curing room for 28 days

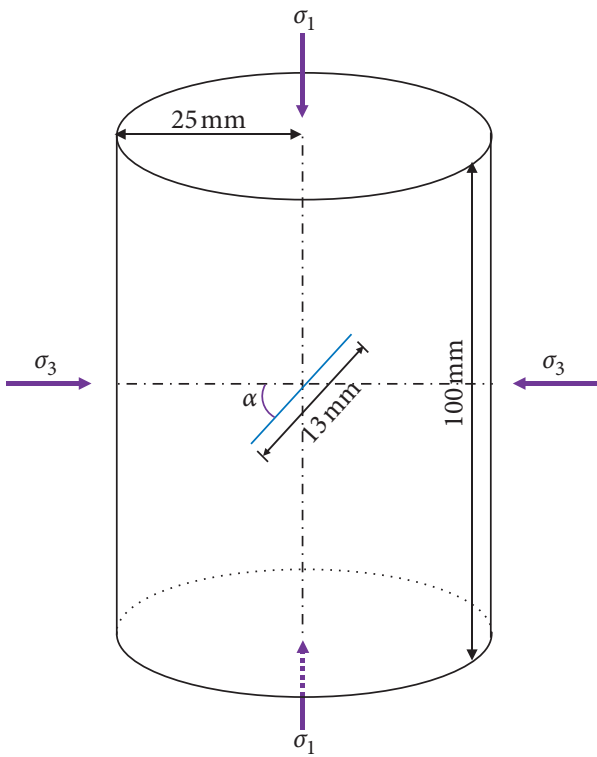

Figure 1: Triaxial compression test on a rock mass with a preexisting fissure. $\sigma_{1}$ and $\sigma_{2}$ are the axial stress and confining pressure, respectively. $\alpha$ denotes the inclination angle of the preexisting fissure with reference to the horizontal axis.

after 24 hours in the room environment. A core-drilling machine and a grinding machine were employed to prepare cylindrical specimens with preexisting fissures at inclinations of $0^{\circ}, 30^{\circ}, 60^{\circ}$, and $90^{\circ}$. In this study, the cylindrical specimens were fabricated with dimensions of $100 \mathrm{~mm}$ (height) $\times 50 \mathrm{~mm}$ (diameter). The fissure geometry was determined by two geometrical parameters, including the fissure inclination $\left(0^{\circ}\right.$, $\left.30^{\circ}, 60^{\circ}, 90^{\circ}\right)$ and the fissure length $(13 \mathrm{~mm})$. The preexisting fissures were formed using high-strength steel sheets that have a thickness of $0.2 \mathrm{~mm}$ and a length of $13 \mathrm{~mm}$. The mechanical parameters are shown in Table 1 .

2.2. MTS815.03 Equipment. We adopted the MTS815.03 servo-controlled rock mechanical test system (Figure 3). All of the processes of specimens being subjected to triaxial compression are controlled by a microcomputer so that the data are collected and processed automatically. MTS815.03 is equipped with three independent servo systems that control the axial compression, the confining pressure, and the pore water pressure.

(1) The basic principle of the MTS815.03 servo system is shown in Figure 4.

(2) Basic functions of the MTS815.03 servo control system are listed as follows:

(1) Uniaxial compression test

(2) Triaxial compression test

$$
\left.\begin{array}{l}
\sigma_{1}>\sigma_{2}=\sigma_{3} \\
\sigma_{1}=\sigma_{2}>\sigma_{3}
\end{array}\right\} \text { traditional triaxial compression. }
$$

(3) Pore water pressure test.

(4) Water permeability test. 


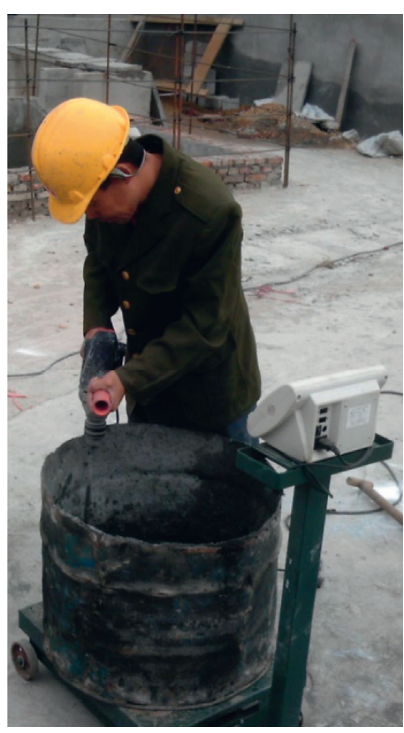

(a)
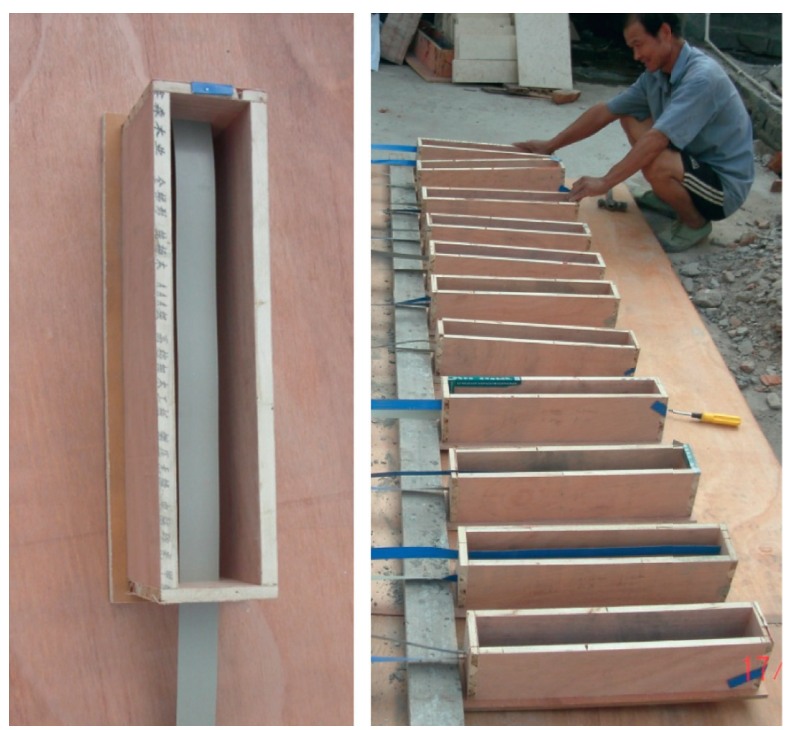

(b)

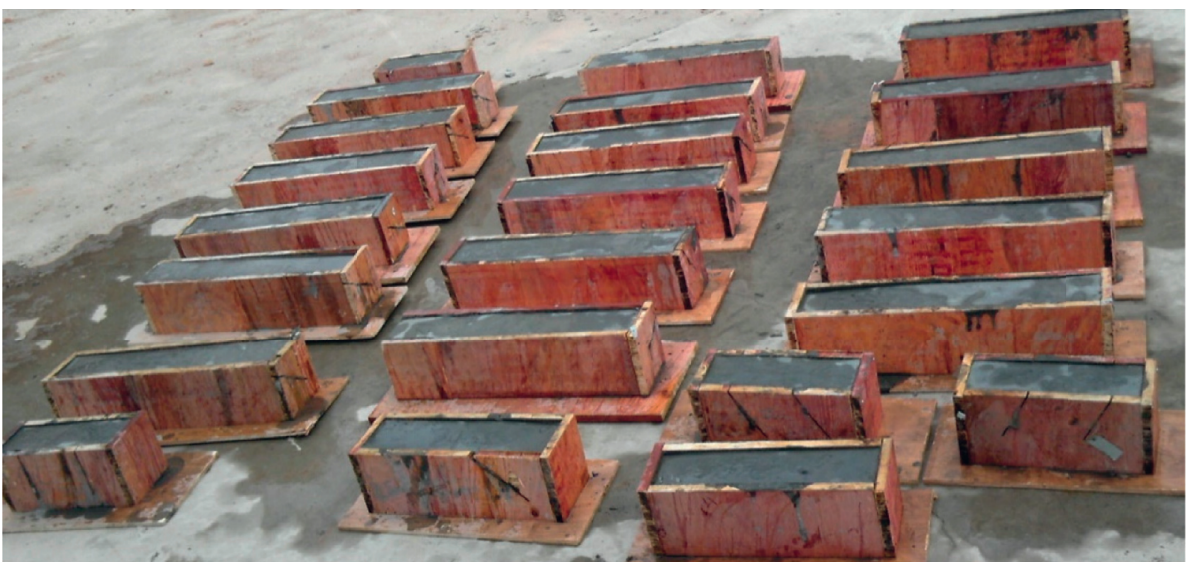

(c)

Figure 2: Continued. 

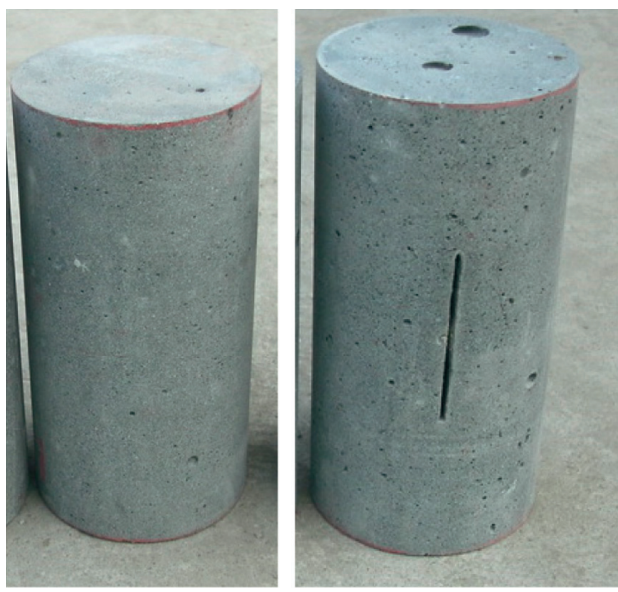

(d)

Figure 2: Specimen preparation process. (a) Stirring the mixture material. (b) The specified jointed mold. (c) Pouring the mixed synthetic rock-like material into the mold. (d) Standard specimens after 28 days of curing.

TABLE 1: Mechanical parameters of the high-strength steel sheet.

\begin{tabular}{lcccc}
\hline Tensile strength $(\mathrm{MPa})$ & Yield strength $(\mathrm{MPa})$ & Elongation & Percent reduction in area & Hardness \\
\hline$\geq 735$ & $\geq 540$ & $\geq 12$ & $\geq 40$ & $\geq 217$ \\
\hline
\end{tabular}

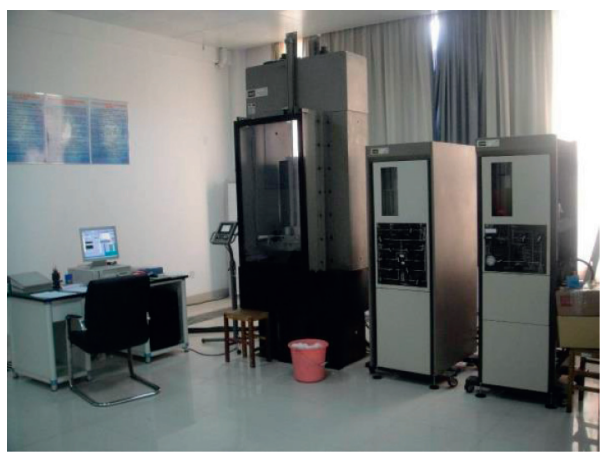

(a)

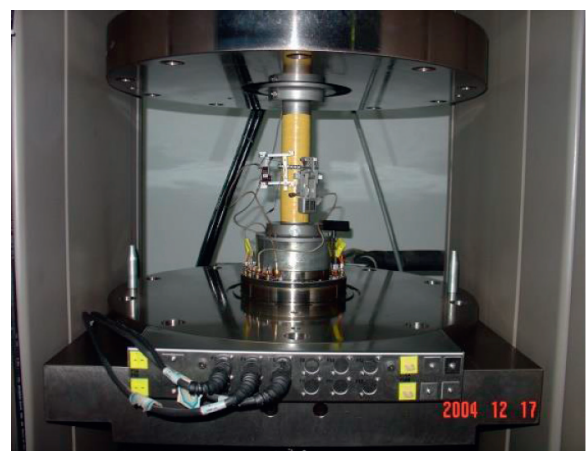

(b)

Figure 3: (a) MTS815.03 servo-controlled test system. (b) Specimen and sensors.

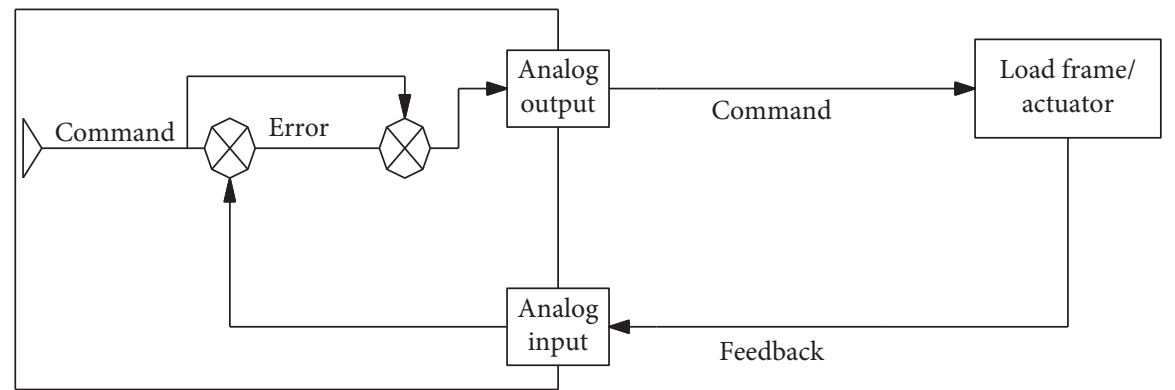

FIGURE 4: MTS815.03 servo control principle.

The axial stress and confining pressure were servocontrolled by stress and displacement loading modes. The axial and circumferential strains were determined by monitoring the axial and circumferential deformation through the corresponding extensometers. Following the experimental procedures of the ISRM methods [32], 
uniaxial/triaxial compression and Brazilian tests were carried out on cylindrical and disc-like specimens without preexisting fissures. Table 2 lists the mechanical properties of the cast mortar.

\section{Result Analyses}

3.1. Introduction to the Loading and Unloading Paths. For the purpose of the study, two types of triaxial compression tests were conducted, which are as follows.

3.1.1. Type I: Conventional Triaxial Compression. Conventional triaxial compression tests were first conducted. Preloading was initially applied to ensure that the specimen was tightly sandwiched between the upper and lower platens. The confining pressure $\left(\sigma_{3}\right)$ was increased to $14 \mathrm{MPa}$ at a stress loading rate of $0.1 \mathrm{MPa} / \mathrm{s}(o \longrightarrow a$ in Figure $5(\mathrm{a}))$ and then was held constant. The axial stress $\left(\sigma_{1}\right)$ was applied continuously through a displacement loading rate of $0.2 \mathrm{~mm} /$ min until the specimen failed completely $(a \longrightarrow b \longrightarrow c$ in Figure 5(a)).

3.1.2. Type II: Triaxial Compression with Prepeak Circumferential Unloading. The type II test consists of four procedures:

(1) The preloading and confining pressure $\left(\sigma_{3}\right)$ were applied in the same manner as in the type I test (o $\longrightarrow a$ in Figure 5(b)).

(2) The axial stress $\left(\sigma_{1}\right)$ was increased to the unloading point $(a \longrightarrow d$ in Figure $5(\mathrm{~b})$ ), which equals $70 \%$ of the average failure strength of the specimens under the type I test [33].

(3) The axial stress $\left(\sigma_{1}\right)$ was kept constant. The confining pressure $\left(\sigma_{3}\right)$ was reduced at a rate of $0.05 \mathrm{MPa} / \mathrm{s}$ until the specimen failed $(d \longrightarrow e \longrightarrow f$ in Figure 5(b)).

(4) The confining pressure $\left(\sigma_{3}\right)$ was kept constant. The axial stress $\left(\sigma_{1}\right)$ was controlled through the displacement loading mode until the deviatoric stress $\left(\sigma_{1}-\sigma_{3}\right)$ did not decrease as the axial strain increased $(f \longrightarrow g$ in Figure 5(b))

3.2. Strength and Deformation. Figure 6 shows the stressstrain curves of specimens with different inclinations of the preexisting fissures under type I and II tests. Note that the failure strength means the maximum value of axial stress before the crack growth and penetration stages, and the residual strength is defined as the residual ability of being resistant to external loading. And the residual strength is recognized as the stable stress value when the axial strain is increasing during the residual stage.

\subsection{The Mechanical Responses of the Specimens under Type I and II Tests Are Different}

(1) Under the type I test, the stress-strain curves in the postpeak stage exhibit a zigzag behavior. For
TABLE 2: Mechanical properties of the cast mortar.

\begin{tabular}{lccccc}
\hline $\mathrm{E}(\mathrm{GPa})$ & $v$ & $\sigma_{C}(\mathrm{MPa})$ & $\sigma_{t}(\mathrm{MPa})$ & $c(\mathrm{MPa})$ & $\phi\left(^{\circ}\right)$ \\
\hline 14.2 & 0.12 & 70.1 & 2.16 & 20.7 & 35 \\
\hline
\end{tabular}

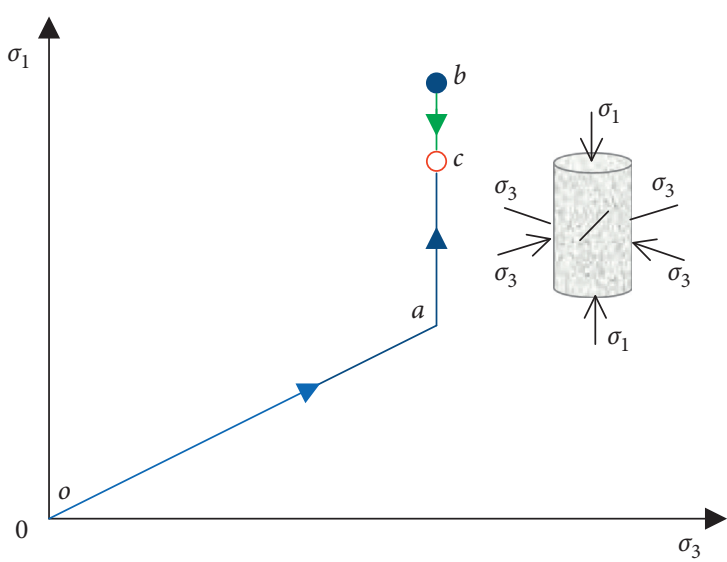

(a)

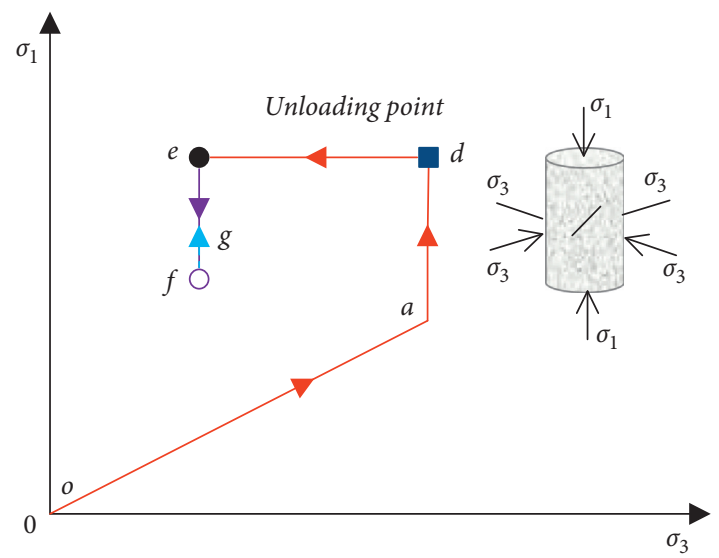

(b)

Figure 5: Loading paths of the type I and II tests (after Yang et al. [33]). (a) Type I: conventional triaxial compression. (b) Type II: triaxial compression with prepeak circumferential unloading. Loading path of the type I test: $o a \longrightarrow a b \longrightarrow b c$. Loading path of the type II test: $o a \longrightarrow a d \longrightarrow d e \longrightarrow e f \longrightarrow f g . \sigma_{1}$ and $\sigma_{3}$ denote the axial stress and confining pressure, respectively.

specimens with a preexisting fissure inclined at $0^{\circ}$ or $30^{\circ}$, the maximum stress values after the failure strength are higher than the failure strength values. The maximum stress value in the postpeak stage roughly equals the failure strength value when the fissure inclination is $60^{\circ}$. When the fissure inclination is $90^{\circ}$, the maximum stress value in the postpeak stage is lower than the failure strength value. However, the stress-strain curves under the type II test are different from those under the type I test. The stress-strain curves in the postpeak stage under the type II test are smooth with apparent ductility after the deviatoric stress $\left(\sigma_{1}-\sigma_{3}\right)$ drops.

(2) Under the type II test, the failure strength values of the specimens remain almost constant after the 


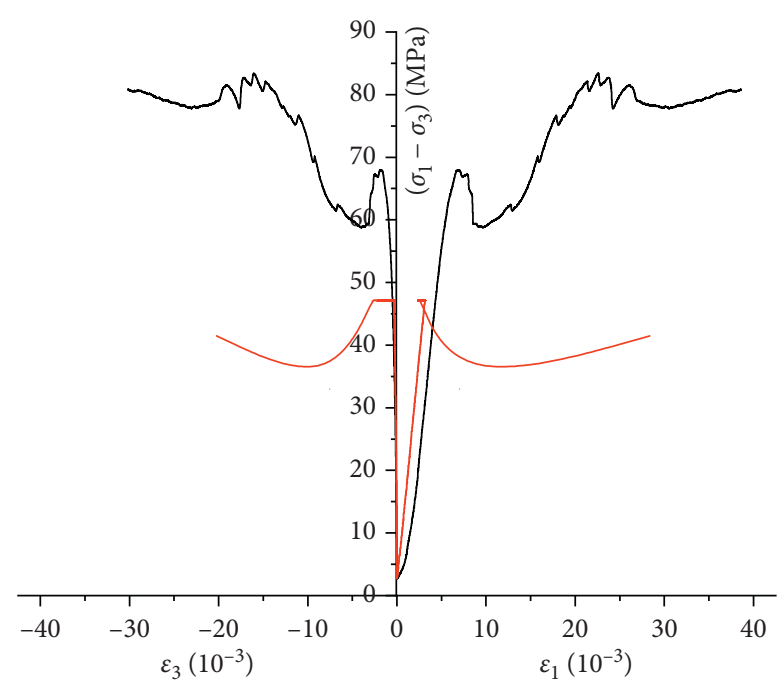

A0-2 loading A0-4 unloading

(a)

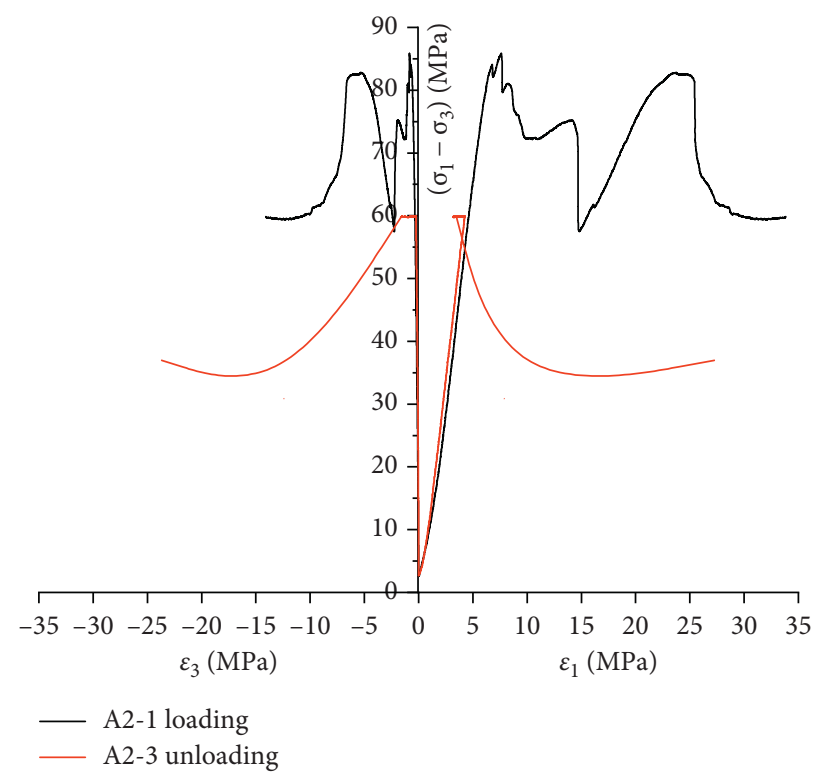

(c)

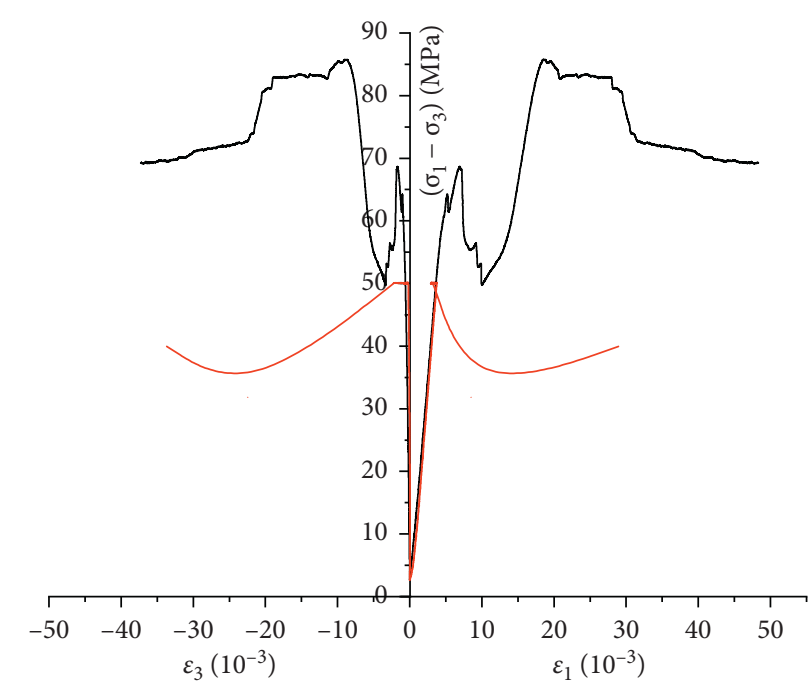

A1-1 loading

__ A1-2 unloading

(b)

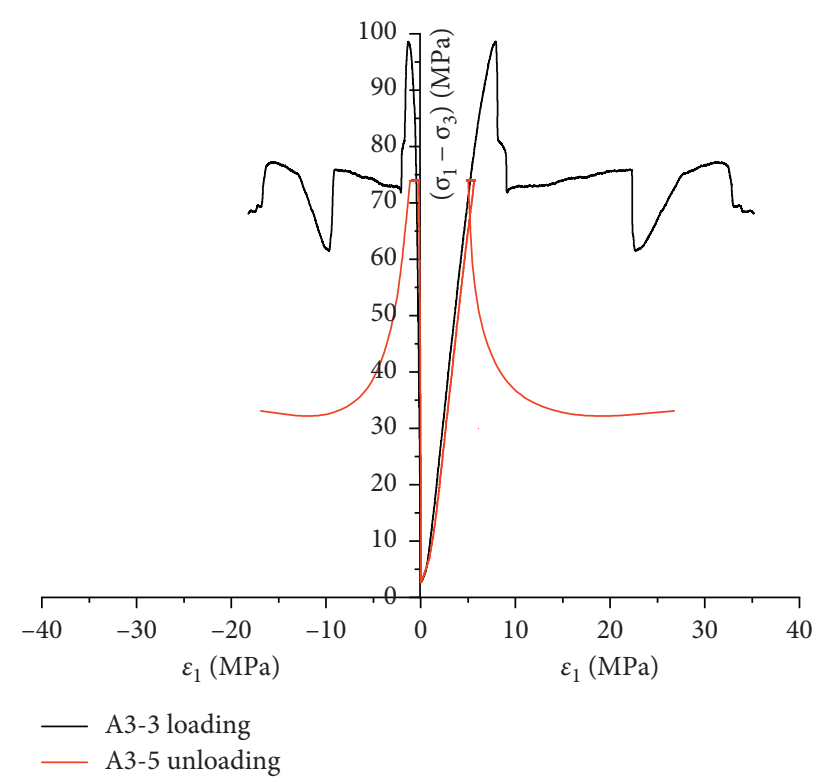

(d)

FiguRE 6: Stress-strain curves of rock-like specimens with preexisting fissures under type I and II tests. (a) $\alpha=0^{\circ}$. (b) $\alpha=30^{\circ}$. (c) $\alpha=60^{\circ}$. (d) $\alpha=90^{\circ}$.

circumferential unloading begins. In other words, the failure strength values of the specimens under the type II test roughly equal the stress values at the unloading point.

(3) Under the type II test, the axial and circumferential strains ( $\varepsilon_{1}$ and $\varepsilon_{3}$, respectively) of the specimens exhibit a remarkable "platform effect"; that is, the deviatoric stress values $\left(\sigma_{1}-\sigma_{3}\right)$ are nearly unchanged, but the strains vary appreciably. At the beginning of the circumferential unloading, the axial strain $\left(\varepsilon_{1}\right)$ rebounds and stretches. A noticeable expansion of the circumferential strain $\left(\varepsilon_{3}\right)$ was observed.
Table 3 details the failure strength $\left(\sigma_{p}\right)$ and residual strength $\left(\sigma_{r}\right)$ values of the tested specimens. The failure strength and residual strength values of the specimens are closely related to the fissure inclination. Both strengths under the type II test are lower than those under the type I test. Figure 7 shows the dependence of the failure residual strength values on the fissure inclination. The failure strength values of the specimens increase gradually as the fissure inclination increases for both types of tests (Figure 7(a)). The failure strength values of the type I test increase slowly when the fissure inclination increases from $0^{\circ}$ to $30^{\circ}$. The increasing rate of the failure strength grows higher when the fissure inclination varies from $30^{\circ}$ to $90^{\circ}$. 
TABLE 3: Strength of the rock-like specimens with varying fissure inclinations under type I and II tests.

\begin{tabular}{lcccc}
\hline Specimen & Inclination $\alpha\left(^{\circ}\right)$ & Failure strength $(\mathrm{MPa})$ & Residual strength $(\mathrm{MPa})$ & Type \\
\hline A0-2 & 0 & 67.95 & 80.76 & I \\
A0-4 & 0 & 47.20 & 69.47 & II \\
A1-1 & 30 & 68.67 & 39.96 & I \\
A1-2 & 30 & 50.14 & 59.87 & II \\
A2-1 & 60 & 85.86 & 36.96 & I \\
A2-3 & 60 & 59.89 & 68.08 & II \\
A3-3 & 90 & 98.62 & 33.07 & I \\
A3-5 & 90 & 74.04 & II \\
\hline
\end{tabular}

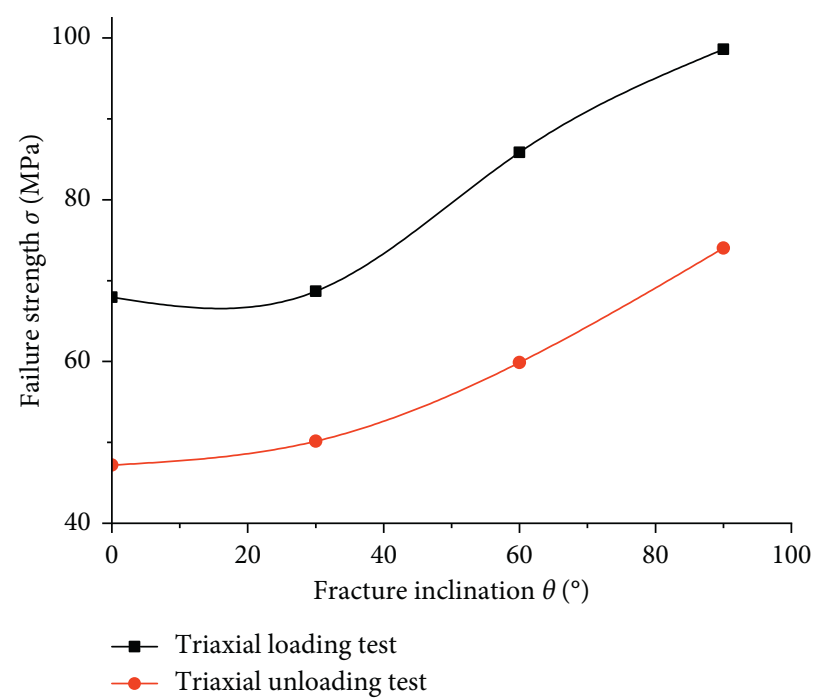

(a)

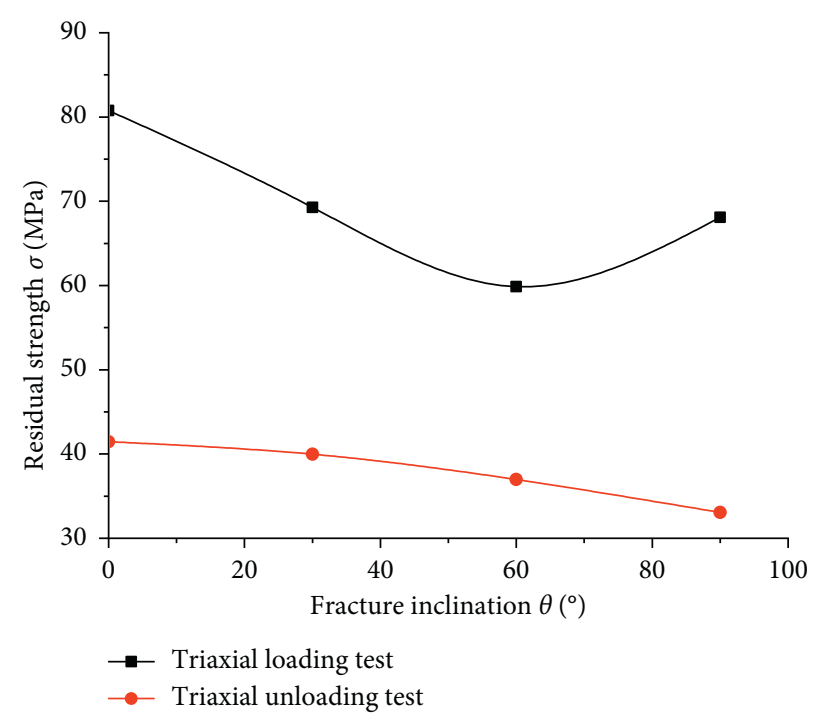

(b)

FigURE 7: (a) Failure strength values and (b) residual strength values of the rock-like specimens with varying fissure inclinations under type I and II tests.

Figure 8 gives the linear relationship between the failure strength values and the fissure inclination as follows:

$$
\sigma_{p}=0.3009 \alpha+44.278
$$

Figure 7(b) shows that the residual strength values of the specimens decrease first, followed by increases with the fissure inclination under the type I test. The residual strength values are negligible when the fissure inclination is $60^{\circ}$. However, the residual strength values of the specimens decrease continuously when the fissure inclination increases under the type II test. The relationship between the residual strength values and the fissure inclination is approximately linear (Figure 8):

$$
\sigma_{r}=-0.094 \alpha+42.098 .
$$

The correlation coefficient between the failure strength and the fissure inclination and that between the residual strength and the fissure inclination are higher than 0.92 , indicating a strong linear dependency (Figure 8).

Figure 9 shows the relationships between the confining pressure and the axial strain under the type II test. Both the axial and circumferential strain values of the specimens are small at the point of circumferential unloading. The maximum axial strain value is approximately $5 \times 10^{-3}$ and the circumferential strain is lower than $1 \times 10^{-3}$, indicating that the specimen is experiencing elastic deformation when the circumferential unloading commences. During the unloading, the axial and circumferential strain values of the specimens do not vary remarkably as the confining pressure decreases. When the confining pressure approaches zero, the strain of the specimen begins to increase continuously and the specimen fails brittlely.

We use the unloading ratio of confining pressure $\left(\Delta \sigma_{3}\right)$ and the variation of deformation modulus $(\Delta E)$ to further explore the deformation features of the rock-like specimens with a preexisting fissure during the circumferential unloading process. The unloading ratio of the confining pressure $\left(\Delta \sigma_{3}\right)$ is defined as

$$
\Delta \sigma_{3}=\frac{\sigma_{3}^{i}-\sigma_{u}}{\sigma_{u}} \times 100 \%,
$$

where $\sigma_{3}^{i}$ is the real-time confining pressure at step $i$ and $\sigma_{u}$ is the confining pressure before circumferential unloading, which is $14 \mathrm{MPa}$ in this study. The variation of deformation modulus $(\Delta E)$ includes the variations of axial and 


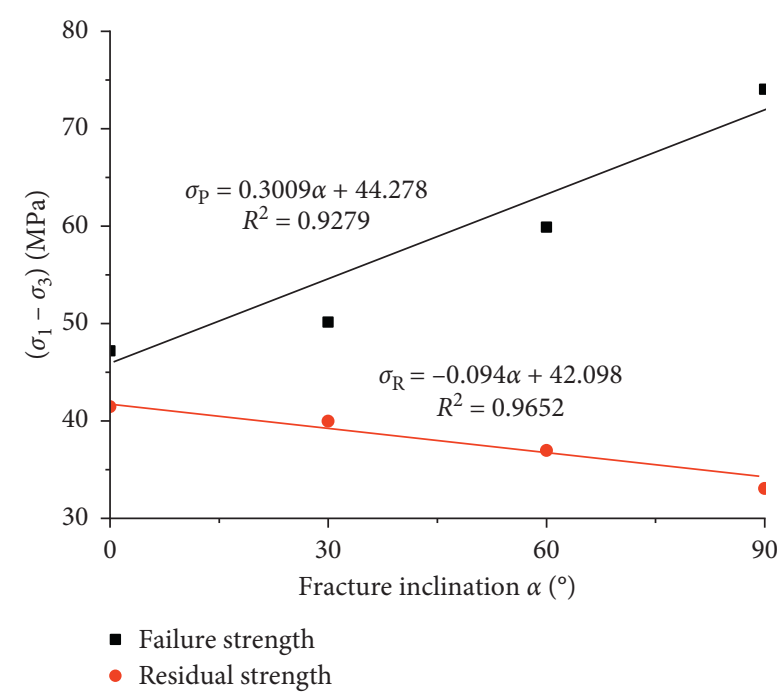

FIGURE 8: Relationship between strength and fissure inclinations under type I and II tests.

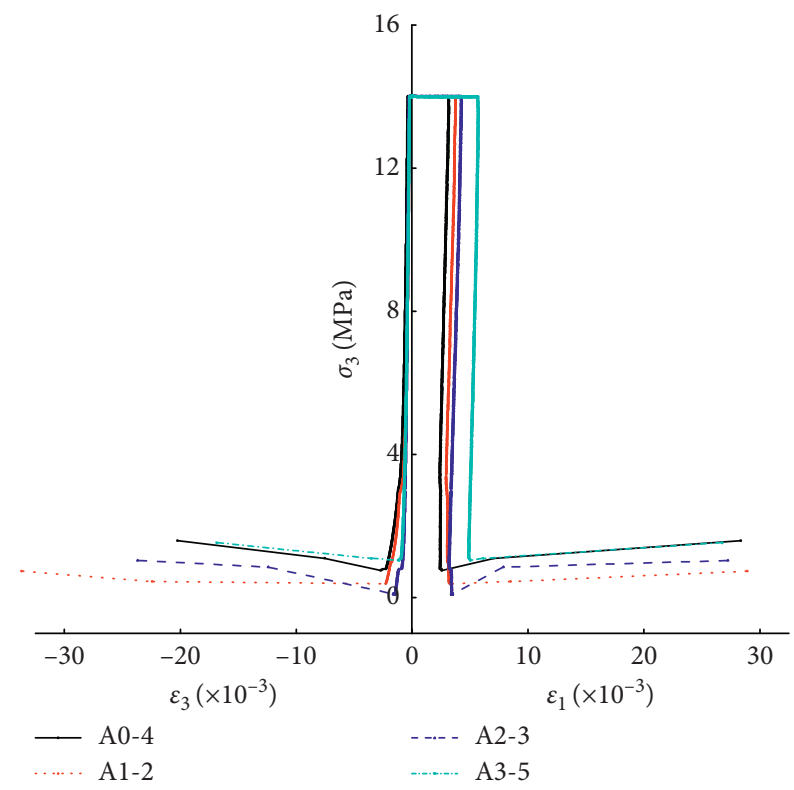

FIGURE 9: Variation of strains during circumferential unloading.

circumferential deformation moduli $\left(\Delta E_{1}\right.$ and $\Delta E_{3}$, respectively), which are separately expressed as

$$
\begin{aligned}
& \Delta E_{1}=\frac{E_{1}^{i}-E_{1}^{0}}{E_{1}^{0}} \times 100 \%, \\
& \Delta E_{3}=\frac{E_{3}^{i}-E_{3}^{0}}{E_{3}^{0}} \times 100 \%,
\end{aligned}
$$

where $E_{1}^{i}$ and $E_{3}^{i}$ are the axial and circumferential deformation moduli at each step of the circumferential unloading stage, respectively, and $E_{1}^{0}$ and $E_{3}^{0}$ are the axial and circumferential deformation moduli before circumferential unloading, respectively. In this study, the deformation modulus is determined as the secant modulus.
Figure 10(a) shows the relationship between the unloading ratio of the confining pressure and the variation of the axial deformation modulus in the circumferential unloading stage. Both the unloading ratio of the confining pressure and the maximum variations of the axial deformation modulus depend heavily on the fissure inclination. Although the unloading ratio of the confining pressure and the variation of axial deformation modulus show a slight zigzag, the relationship between them is a strong linear relationship before the variation of axial deformation modulus peaks. As the unloading ratio of the confining pressure increases, the axial deformation modulus grows gradually. The value of axial deformation modulus of specimen A3-5 with a fissure inclination of $90^{\circ}$ is clearly lower than those of the other three types of specimens, suggesting that the unloading ratio of the confining pressure has a more pronounced effect on the deformation of a specimen. Figure 10(b) shows the relationship between the unloading ratio of the confining pressure and the variation of the circumferential deformation modulus in the circumferential unloading process. The relationship between the unloading ratio of the confining pressure and the variation of the circumferential modulus decreases continuously, which is independent of the fissure inclination.

3.4. Failure Modes. Figure 11(a) shows the failure modes of specimens under type I and II tests. The crack traces of the failed specimens are reidentified such that they are classified as wing cracks, antiwing cracks, and tensile cracks. The rocklike specimens possess the following failure characteristics under the type I test: (1) The specimens exhibit " $X$ "-type shear failures. The lines of the " $X$ " type are from the wing crack and the antiwing crack. (2) In addition to the wing crack and the antiwing crack, a tensile crack that is roughly parallel to the direction of the maximum principal stress is observed. (3) When the fissure inclination is $0^{\circ}$ or $30^{\circ}$, a dense crushing zone appears around the fissure. When the fissure inclination is $60^{\circ}$ or $90^{\circ}$, the breakage traces are clear and regular without noticeable crushing zones. This is consistent with the characteristics of the stress-strain curves after the failure strength values of the type I test. When the fissure inclination is $0^{\circ}$ or $30^{\circ}$, the zigzag section of the stressstrain curve after the failure strength is related to the crack zone of the specimen and strain hardening is observed. When the fissure inclination is $60^{\circ}$ or $90^{\circ}$, the stress-strain curve undergoes a brief zigzag after the failure strength, with a tendency of strain ductility. Few secondary crack traces are observed.

Figure 11(b) shows the failed specimens under the type II test, which exhibit the following features: (1) When the fissure inclination is $0^{\circ}$ or $30^{\circ}$, the specimens exhibit composite tensile-shear failures. When the fissure inclination is $60^{\circ}$, the shear-slip failure along the fissure plane dominates the failure mode of the specimens. When the fissure inclination is $90^{\circ}$, the specimens display tensile failure. (2) Except for specimen A2-3, which has a fissure inclination of $60^{\circ}$, the tensile cracks develop along the fissure plane of the specimen that are parallel to the direction of the maximum principal 


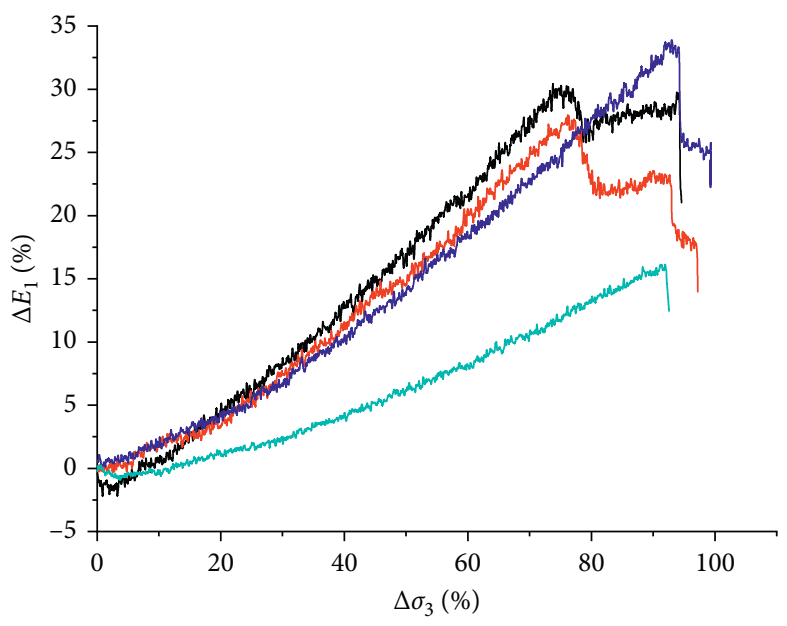

$\begin{array}{ll}\mathrm{A} 0-4 & -\mathrm{A} 2-3 \\ \mathrm{~A} 1-2 & \mathrm{~A} 3-5\end{array}$

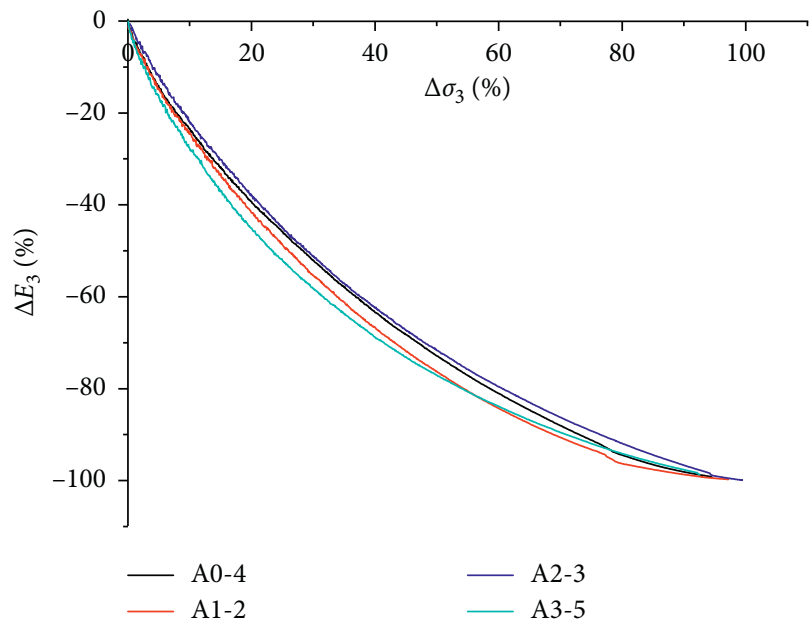

(a)

(b)

FIGURE 10: Relationships between the unloading ratios of the confining pressure and the variations of the deformation modulus. (a) Unloading ratios of the confining pressure vs variations of the axial deformation modulus. (b) Unloading ratios of the confining pressure vs variations of the circumferential deformation modulus.
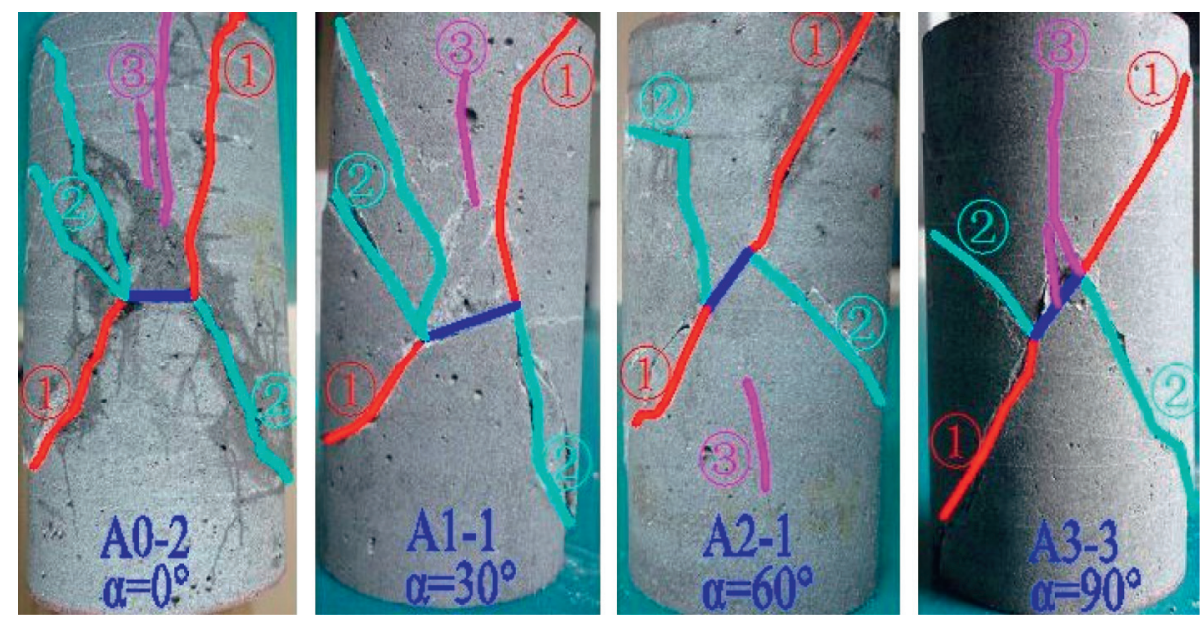

(a)
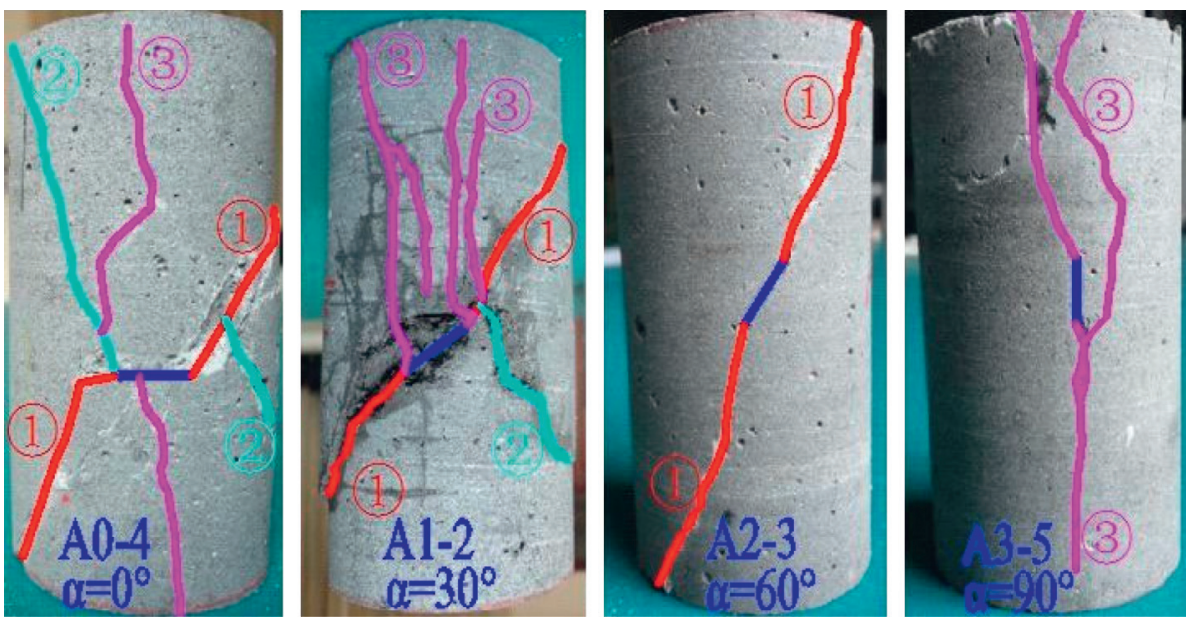

(b)

FIGURE 11: Failure modes of rock-like specimens with preexisting fissures under type I (a) and II (b) tests. (1), (2), and (3) represent wing cracks, antiwing cracks, and tensile cracks, respectively. 
stress. The tensile cracks extend to both ends of the specimens. (3) The failures of the specimens are accompanied by ruptures with clear audible sounds, suggesting a typical brittle tensile failure.

The comparison between Figures 11(a) and 11(b) shows the following: (1) The failure modes of the rock-like specimens under the type I test are fundamentally different from those under the type II test. When the fissure inclination is $0^{\circ}$ or $30^{\circ}$, the failure modes of the specimens transform from " $X$ "-type shear failures to tensile-shear composite failures. When the fissure inclination is $60^{\circ}$, the failure mode of the specimens transforms from an " $X$ "-type shear failure to a shear-slip failure along the fissure plane. However, when the fissure inclination is $90^{\circ}$, the failure mode of the specimens is transformed to pure tensile failure. (2) Compared to the specimens under the type I test, the tensile cracks under all the fissure inclinations are well developed under the type II test. Under the type I test, tensile cracks appear in some regions of the specimens that are difficult to extend to both ends of the specimen. In contrast, the tensile cracks are well extended to both ends of the specimen with noticeable tensile features under the type II test.

\subsection{Discussion}

3.5.1. Analysis of the Stress-Strain Curves of the Triaxial Compression Tests. The stress-strain curves of the specimens with open-through fissures show multipeak characteristics under triaxial compression. These can be divided into seven stages: fissure compaction, elastic deformation, crack growth and penetration, strain softening, void recompaction, progressive failure, and a residual stage. The preexisting fissure is mainly compacted during the initial compaction stage; the brittle failure stage is followed by ideal strain softening and later a void recompaction process that is mainly caused by inner void and pore compaction. In addition, the progressive failure continues until the residual stage occurs.

3.5.2. Generation Mechanism of Antiwing Cracks. Antiwing cracks, after discovery by Dr. Wong, have been observed by other researchers. In this paper, we observed antiwing cracks after the fractured specimens were subjected to triaxial compression loading. However, for the unloading triaxial compression condition, we only observed antiwing cracks after the fractured specimens containing gentle fissure angles were subjected to unloading triaxial compression. It can be concluded that the combined action of compression and shear stress leads to the generation of antiwing cracks. For the loading triaxial compression tests, the joint action of the confining pressure and the axial stress produces the compressive shear stress, while for unloading triaxial compression tests, the specimens are mainly subjected to axial compression after the confining pressure has declined; thus, the tensile failure mode dominates.

\section{Conclusions}

We carried out conventional triaxial compression (type I) and triaxial compression with prepeak circumferential unloading (type II) tests on the rock-like specimens with preexisting fissures. The stress-strain relationship, strength, deformation, and failure modes of the specimens were studied. The following main conclusions are drawn:

(1) The stress-strain curves in the postpeak stage of the rock-like specimens with preexisting fissures are characterized by a zigzag behavior under the type I test. The trends of the zigzag curves are closely related to the fissure inclinations. The stress drops in the postpeak stage under the type II test.

(2) The failure strength under the type II test roughly equals the stress at the unloading point. The unloading process of the rock-like specimens is associated with a remarkable variation of strains.

(3) The fissure inclination strongly influences the failure and residual strength values under the types I and II tests. Under the type I test, with increasing fissure inclination, the failure strength increases. The residual strength values decrease first and then increase. Under the type II test, as the fissure inclination increases, the failure strength values increase linearly, while the residual strength values decrease linearly.

(4) The unloading ratio of the confining pressure and the variation of the deformation modulus quantify the deformation under the type II test. For the rock-like specimens with a fissure inclination of $0^{\circ}$ or $30^{\circ}$, there is a linear relationship between the unloading ratio of confining pressure and the variation of the axial deformation modulus when the unloading ratio of the confining pressure is less than $75 \%$. For specimens with a fissure inclination of $60^{\circ}$ or $90^{\circ}$, a linear relationship exists between the two descriptors when the unloading ratio of the confining pressure is lower than $92 \%$.

(5) The failure modes of rock-like specimens with preexisting fissures differ fundamentally under type I and II tests. The specimens mainly exhibit an "X"type shear failure under the type I test, while the cracks of the specimens are strongly affected by the fissure inclination under the type II test. When the preexisting fissure is inclined at a low angle of $0^{\circ}$ or $30^{\circ}$, the failure is a composite of tensile-shear cracking. When the fissure inclination is $60^{\circ}$, the failure is dominated by shear slip along the fissure plane. When the inclination is $90^{\circ}$, the tensile cracks dominate the failure. These findings support the prediction of rock mass failures in deep underground rock engineering projects.

\section{Data Availability}

The data used to support the findings of this study are available from the corresponding author upon request. 


\section{Conflicts of Interest}

The authors declare that they have no conflicts of interest.

\section{Acknowledgments}

This work was supported by the Natural Science Fund of Hubei Province (grant number 2015CF-B667) and the National Natural Science Foundation of China (grant number 51678066).

\section{References}

[1] C. D. Martin, P. K. Kaiser, and R. Christiansson, "Stress, instability and design of underground excavations," International Journal of Rock Mechanics and Mining Sciences, vol. 40, no. 7-8, pp. 1027-1047, 2003.

[2] J. Shang, Persistence and Tensile Strength of Incipient Rock Discontinuities, University of Leeds, Leeds, UK, Doctoral dissertation, 2016.

[3] J. Shang, S. R. Hencher, and L. J. West, "Tensile strength of geological discontinuities including incipient bedding, rock joints and mineral veins," Rock Mechanics and Rock Engineering, vol. 49, no. 11, pp. 4213-4225, 2016.

[4] J. Shang, L. J. West, S. R. Hencher, and Z. Zhao, "Tensile strength of large-scale incipient rock joints: a laboratory investigation," Acta Geotechnica, vol. 13, no. 4, pp. 869-886, 2018.

[5] T. Xiao, M. Huang, C. Cheng, and Y. He, "Experimental investigation on the mechanical characteristics and deformation behaviour of fractured rock-like material with one single fissure under the conventional triaxial compression," Shock and Vibration, vol. 2018, Article ID 2608639, 11 pages, 2018.

[6] F. Peng, F. Dai, Yi Liu, N. Xu, and T. Zhao, "Influence of two unparallel fissures on the mechanical behaviours of rock-like specimens subjected to uniaxial compression," European Journal of Environmental and Civil Engineering, vol. 22, 2018.

[7] L. N. Y. Wong and H. H. Einstein, "Crack coalescence in molded gypsum and carrara marble: Part 2-microscopic observations and interpretation," Rock Mechanics and Rock Engineering, vol. 42, no. 3, pp. 513-545, 2008.

[8] G. M. Elliott and E. T. Brown, "Further development of a plasticity approach to yield in porous rock," International Journal of Rock Mechanics and Mining Sciences \& Geomechanics Abstracts, vol. 23, no. 2, pp. 151-156, 1986.

[9] A.-Z. Hua and M.-Q. You, "Rock failure due to energy release during unloading and application to underground rock burst control," Tunnelling and Underground Space Technology, vol. 16, no. 3, pp. 241-246, 2001.

[10] M. Tao, X. Li, and C. Wu, "Characteristics of the unloading process of rocks under high initial stress," Computers and Geotechnics, vol. 45, pp. 83-92, 2012.

[11] Q. Meng, M. Zhang, L. Han, H. Pu, and T. Nie, "Effects of acoustic emission and energy evolution of rock specimens under the uniaxial cyclic loading and unloading compression," Rock Mechanics and Rock Engineering, vol. 49, no. 10, pp. 3873-3886, 2016.

[12] Q.-L. Ding, F. Ju, X.-B. Mao, D. Ma, B.-Y. Yu, and S.-B. Song, "Experimental investigation of the mechanical behavior in unloading conditions of sandstone after high-temperature treatment," Rock Mechanics and Rock Engineering, vol. 49, no. 7, pp. 2641-2653, 2016.
[13] J. Chen, D. Jiang, S. Ren, and C. Yang, "Comparison of the characteristics of rock salt exposed to loading and unloading of confining pressures," Acta Geotechnica, vol. 11, no. 1, pp. 221-230, 2016.

[14] Q. Liu, Y. Cheng, K. Jin, Q. Tu, W. Zhao, and R. Zhang, "Effect of confining pressure unloading on strength reduction of soft coal in borehole stability analysis," Environmental Earth Sciences, vol. 76, no. 4, 2017.

[15] Z. T. Bieniawski, "Mechanism of brittle fracture of rock: Part II-experimental studies," International Journal of Rock Mechanics and Mining Sciences \& Geomechanics Abstracts, vol. 4, no. 4, pp. 407-423, 1967.

[16] E. Z. Lajtai, "Brittle fracture in compression," International Journal of Fracture, vol. 10, no. 4, pp. 525-536, 1974.

[17] J. M. Willemse E, C. P. Peacock D, and A. Aydin, "Nucleation and growth of strike-slip faults in limestones from Somerset, U.K," Journal of Structural Geology, vol. 19, no. 12, pp. 1461-1477, 1997.

[18] Y.-P. Li, L.-Z. Chen, and Y.-H. Wang, "Experimental research on pre-cracked marble under compression," International Journal of Solids and Structures, vol. 42, no. 9-10, pp. 25052516, 2005.

[19] L. N. Y. Wong and H. H. Einstein, "Systematic evaluation of cracking behavior in specimens containing single flaws under uniaxial compression," International Journal of Rock Mechanics and Mining Sciences, vol. 46, no. 2, pp. 239-249, 2009.

[20] L. G. Zhao, J. Tong, and M. C. Hardy, "Prediction of crack growth in a nickel-based superalloy under fatigue-oxidation conditions," Engineering Fracture Mechanics, vol. 77, no. 6, pp. 925-938, 2010.

[21] Y. Liu, F. Dai, P. Feng, and N. Xu, "Mechanical behavior of intermittent jointed rocks under random cyclic compression with different loading parameters," Soil Dynamics and Earthquake Engineering, vol. 113, pp. 12-24, 2018.

[22] P. Feng, F. Dai, Y. Liu, N. Xu, and P. Fan, "Effects of coupled static and dynamic strain rates on mechanical behaviors of rock-like specimens containing pre-existing fissures under uniaxial compression," Canadian Geotechnical Journal, vol. 55, no. 5, pp. 640-652, 2018.

[23] H. C. R. Wong and K. T. Chau, "Crack coalescence in a rocklike material containing two cracks," International Journal of Rock Mechanics and Mining Sciences, vol. 35, no. 2, pp. 147-164, 1998.

[24] L. N. Y. Wong and H. H. Einstein, "Crack coalescence in molded gypsum and carrara marble: Part 1. Macroscopic observations and interpretation," Rock Mechanics and Rock Engineering, vol. 42, no. 3, pp. 475-511, 2009.

[25] S. P. Steif, "Crack extension under compressive loading," Engineering Fracture Mechanics, vol. 20, no. 3, pp. 463-473, 1984.

[26] H. Horii and S. Nemat-Nasser, "Compression-induced microcrack growth in brittle solids: axial splitting and shear failure," Journal of Geophysical Research, vol. 90, no. B4, pp. 3105-3125, 1985.

[27] M. F. Ashby and S. D. H. N. Cooksley, "The failure of brittle solids containing small cracks under compressive stress states," Acta Metallurgica, vol. 34, no. 3, pp. 497-510, 1986.

[28] J. M. Kemny, "A model for non-linear rock deformation under compression due to sub-critical crack growth," International Journal of Rock Mechanics and Mining Sciences \& Geomechanics Abstracts, vol. 28, no. 6, pp. 459-467, 1991.

[29] C. A. Tang, P. Lin, R. H. C. Wong, and K. T. Chau, "Analysis of crack coalescence in rock-like materials containing three flaws-Part II: numerical approach," International Journal of 
Rock Mechanics and Mining Sciences, vol. 38, no. 7, pp. 925-939, 2001.

[30] H.-Q. Li and L. N. Y. Wong, "Numerical study on coalescence of pre-existing flaw pairs in rock-like," Material. Rock Mechanics and Rock Engineering, vol. 47, no. 6, pp. 2087-2105, 2014.

[31] P. Feng, F. Dai, Y. Liu, N.-w. Xu, and H.-b. Du, "Coupled Effects of Static-Dynamic Strain Rates on the Mechanical and Fracturing Behaviors of Rock-like Specimens Containing Two Unparallel Fissures," Engineering Fracture Mechanics, vol. 207, 2018.

[32] Z. T. Bieniawski and I. Hawkes, "International society for rock mechanics commission on standardization of laboratory and field tests suggested methods for determining tensile strength of rock materials," International Journal of Rock Mechanics and Mining Sciences \& Geomechanics Abstracts, vol. 15, no. 6, pp. 319-368, 1978.

[33] S.-Q. Yang, H.-W. Jing, and S.-Y. Wang, "Experimental investigation on the strength, deformability, failure behavior and acoustic emission locations of red sandstone under triaxial compression," Rock Mechanics and Rock Engineering, vol. 45, no. 4, pp. 583-606, 2012. 